[Agr. Biol. Chem., Vol. 31, No. 7; p. 823 830, 1967]

\title{
Studies on the Decomposition of Sinalbin
}

\section{Part II. The Decomposition Products of Sinalbin and their Degradation Pathways}

\author{
By Shunro Kawakishi, Mitsuo Namiki, Hiroyuki Watanabe* \\ and Keiichiro Muramatsu* \\ Department of Agricultural Chemistry, Faculty of Agriculture, \\ Nagoya University, Nagoya \\ * Department of Agricultural Chemistry, Faculty of Agriculture, Shizuoka \\ University, Iwata, Shizuoka-ken \\ Received March 6, 1967
}

\begin{abstract}
Total degradation scheme of sinalbin has been clarified. Under physiological condition ( $\mathrm{pH} 5 \sim 7$ ), a major part of $p$-hydroxybenzyl isothiocyanate (I) (white mustard oil) was decomposed to $p$-hydroxybenzyl alcohol (II) and $\mathrm{SCN}^{-}$, and a minor part of I was degradated to di-( $p$-hydroxybenzyl)disulfide through an intermediate (III). Alkaline hydrolysis, UV, IR and mass spectra suggested that the III was $p$-hydroxybenzyl $p$-hydroxybenzyldithiocarbamate, $\mathrm{C}_{15} \mathrm{H}_{15} \mathrm{NO}_{2} \mathrm{~S}_{2}$. The structure was confirmed also by synthesis.

Another decomposition product $(\mathrm{V})$ of sinalbin was isolated from the reaction mixture of sinalbin and myrosinase at $\mathrm{pH} 3.0$ and identified as p-hydroxybenzyl cyanide. Results showed that I, $V$ and sulfur were simultaniously formed from sinalbin under aciclic condition ( $\mathrm{pH} 3 \sim 4$ ).
\end{abstract}

In the previous paper ${ }^{1 !}$ we described that a major part of $p$-hydroxybenzyl isothiocyanate (I), enzymatically formed from sinalbin, was decomposed to $p$-hydroxybenzyl alcohol (II) and $\mathrm{SCN}^{-}$, and a minor part of $\mathrm{I}$ to $\operatorname{di}-(p-$ hydroxybenzyl) disulfide (IV) through an unknown intermediate (III).

On the other hand, under acidic condition ( $\mathrm{pH} 3 \sim 4$ ), it is well known that many kinds of mustard oil glucoside are hydrolyzed with myrosinase to alkyl isothiocyanate and alkyl cyanide. $^{2} \quad$ Recently, 3-indolylacetonitril ${ }^{3,4}$

1) S. Kawakishi and K. Muramatsu, This Journal, 30, 688 (1966).

2) M. G. Ettlinger, G. P. Daeto Jr., B. W. Harrison, T.J. Mabry and C. P. Thompson, Pro. Nat. Acad. Sci. USA, 47, 1875 (1961).

3) R. Gmelin, M. Saarivirta und A. I. Virtanen, Suomen Kemistilehti, B33, 172 (1960).

4) R. Gmelin und A.I. Virtanen, ibid., B34, 15 (1961). and 1-methoxy-3-indolylacetonitril ${ }^{51}$ were identified from glucobrassicin (in cabbage and cauliflower) and neoglucobrassicin (in rutabaga) respectively as their decomposition product in an acidic medium.

The present study was undertaken to isolate and identify the unknown product III, and to see if a nitril derivative was also formed from sinalbin under an acidic condition in order to compare with its degradation pathway under physiological condition.

As shown in thin-layer chromatogram (Fig. 6), III was formed not only in the neutral medium, but in the acidic medium. Furthermore, III was so unstable in alkaline solution ${ }^{11}$ that isolation of III was attempted from the mustard paste buffered at $\mathrm{pH} 4.0$ with $\mathrm{Mc}$ -

5) R. Gmelin und A. I. Virtanen, Acta Chem. Scand., 16, 1378 (1962). 


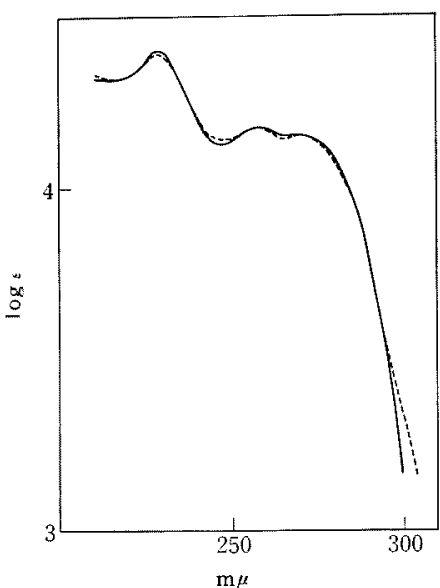

FIG. 1. UV Spectra of the Product III.

_ isolated, -.. synthesized

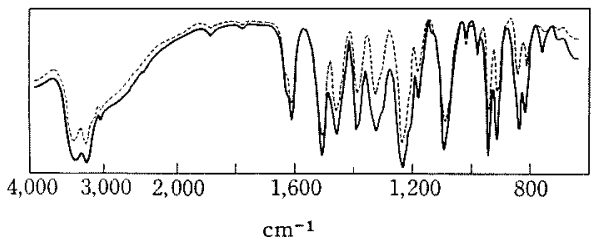

FIG. 2. IR Spectra of the Product III.

__ isolated, - - - synthesized

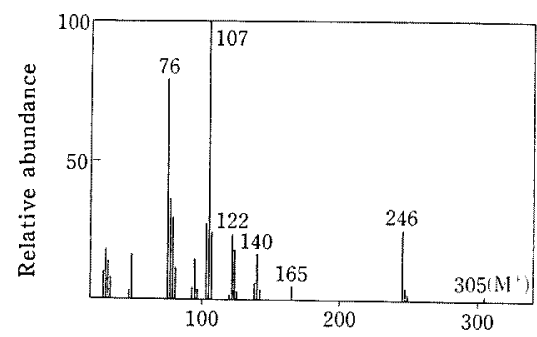

FIG. 3. Mass Spectra of the Product III.

Ilvaine buffer solution. The paste was extracted with ethanol, and the ethanol extracts, after concentration, were reextracted with ether. The ether solution was concentrated and submitted to column chromatography on silica gel. Fractions containing III were combined and purified by repeated column chromatography, and III was obtained as a colorless plate, m.p. $152^{\circ} \mathrm{C}$ (decomp.). The yield of III was $180 \mathrm{mg}$ from $800 \mathrm{~g}$ of defatted mustard powder. The molecular formula $\mathrm{C}_{15} \mathrm{H}_{15} \mathrm{NO}_{2} \mathrm{~S}_{2}$ was assigned to this product from the data of elementary analyses and molecular weight determination (298 by Signer method and 305 by mass spectrometry). IR spectrum (Fig. 2) showed the presence of $p$ substituted phenol group $(3400,1611,1603$, 1236 and $838 \mathrm{~cm}^{-1}$ ) and thioamide group, $-\mathrm{NH}-\mathrm{C}(\mathrm{S})-,\left(3240,1507,1322\right.$ and $\left.1096 \mathrm{~cm}^{-1}\right)$. Color reaction of thiocarbonyl group, $-\mathrm{C}(\mathrm{S})-$, using iodine-azide solution was positive (with evolution of nitrogen gas). III was hydrolyzed with alkali at room temperature to give $p$ hydroxybenzylamine (VI), di-( $p$-hydroxybenzy) disulfide (IV) and $p$-hydroxybenzyl alcohol (II) (small amounts), and furthermore, hydrogen sulfide was developed from the alkaline hydrolyzate upon neutralization, which might be due to the secondary decomposition of carbonyl sulfide formed from III. $p$-Hydroxybenzylamine (VI) was also detected in the reaction mixture of sinalbin and myrosinase by paper chromatography. These data suggested that III contained $p$ $\mathrm{HOC}_{6} \mathrm{H}_{4} \mathrm{CH}_{2} \mathrm{NHC}(\mathrm{S})$ - and $p-\mathrm{HOC}_{6} \mathrm{H}_{4} \mathrm{CH}_{2} \mathrm{~S}-$ groups. Mass spectrum (Fig. 3) also supported this presumption; M/e $76\left(\mathrm{C}_{6} \mathrm{H}_{4}^{+}\right), 107$ $\left(\mathrm{HOC}_{6} \mathrm{H}_{4} \mathrm{CH}_{2}{ }^{+}\right), 122\left(\mathrm{HOC}_{6} \mathrm{H}_{4} \mathrm{CH}_{2} \mathrm{NH}^{+}\right), 140$ $\left(\mathrm{HOC}_{6} \mathrm{H}_{4} \mathrm{CH}_{2} \mathrm{SH}^{+}\right)$and $165\left(\mathrm{HOC}_{6} \mathrm{H}_{4} \mathrm{CH}_{2}-\right.$ $\mathrm{NGS}^{+}$.

The chemical constitution of III was thus proposed to be $p$-hydroxybenzyl $p$-hydroxybenzyldithiocarbamate.

This dithiocarbamate was synthesized for identification of the product III. A. Rieche ${ }^{6}$ described a general synthetic method of dithiocarbamate as follows:

$$
\begin{gathered}
\mathrm{R}-\mathrm{NH}_{2}+\mathrm{CS}_{2} \underset{\mathrm{NaOH}}{\longrightarrow} \mathrm{R}-\mathrm{NHC}(\mathrm{S})-\mathrm{SNa} \stackrel{\mathrm{R}^{\prime} \mathrm{Cl}}{\longrightarrow} \\
\mathrm{R}-\mathrm{NHC}(\mathrm{S})-\mathrm{S}-\mathrm{R}^{\prime}
\end{gathered}
$$

6) A. Rieche, G. Hilgetag, D. Martin und I. Kreyzi, Arch. Pharm., 296, 310 (1963). 


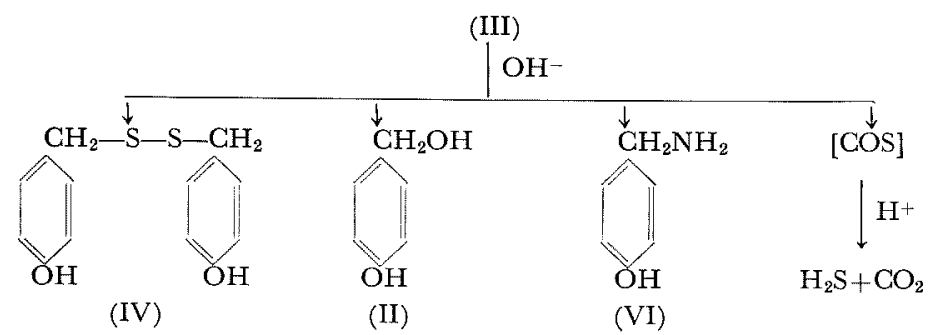

FIG. 4. Alkaline Hydrolysis of the Product III.<smiles>O=Cc1ccc(O)cc1</smiles>

$p$-hydroxybenzaldehyde $\mathrm{NaBH}_{4}$<smiles>OCO</smiles><smiles>Oc1ccccc1</smiles><smiles>CC(=O)[C@H](C)O</smiles>

p-hydroxybenzyl alcohol

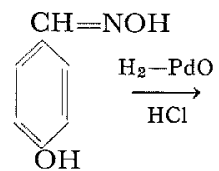

$p$-hydroxybenzaldoxime

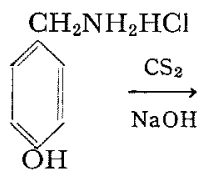

p-hydroxybenzylamine hydrochloride<smiles>S=C(NS)SCc1ccccc1</smiles>

sodium $p$-hydroxybenzyl dithiocarbamate<smiles>Oc1ccccc1</smiles>

p-hydroxybenzyl $p$-hydroxybenzyl<smiles>OCO</smiles><smiles>COC(=O)c1ccc(S(C)(=O)=O)cc1</smiles><smiles>CC(=O)Oc1ccc(CCl)cc1</smiles>

pacetoxybenzyl alcohol

$p$-acetoxybenzyl chloride

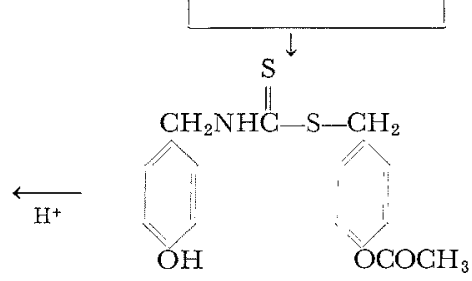

$p$-acetoxybenzyl $p$-hydroxybenzyldithiocarbamate

FIG. 5. Synthesis of $p$-Hydroxybenzyl $p$-Hydroxybenzyldithiocarbamate.

We used this general procedure for synthesis of III. $p$-Hydroxybenzylamine hydrochloride was prepared from $p$-hydroxybenzaldehyde by the method of A. Kjaer et al. ${ }^{7}$ This amine hydrochloride was allowed to react with

7) A. Kjaer and K. Rubinstein, Acta Chem. Scand., 8, 598 (1954). carbon disulfide in sodium hydroxide-methanol solution to give sodium $p$-hydroxybenzyldithiocarbamate. The reaction between this dithiocarbamate and $p$-acetoxybenzyl chloride, ${ }^{81}$ afforded $p$-acetoxybenzyl $p$-hydroxybenzyldithio-

8) R. Grice and L. B. Owen, J. Chem. Soc., 1963 , 1947. 
carbamate, which was hydrolyzed with acetic acid to give a mixture of $p$-hydroxybenzyl $p$ hydroxybenzyldithiocarbamate and $\operatorname{di}-(p$ hydroxybenzyl) disulfide. The former was isolated from the mixture by column chromatography on silica gel using chloroformether, m.p. $153^{\circ} \mathrm{C}$ (decomp.). The synthesized dithiocarbamate was identical with III in all respects, including UV spectrum (Fig. 1), IR spectrum (Fig. 2) and thin-layer chromatographic behaviours.

From these experiments, it was confirmed that the minor part of $p$-hydroxybenzyl isothiocyanate (I) was degraded to di-( $p$-hydroxybenzyl) disulfide (IV) through $p$-hydroxybenzyl $p$-hydroxybenzyldithiocarbamate (III).

Next, the decomposition of sinalbin under various medium $\mathrm{pH}$ was studied.

The reaction mixtures of sinalbin and myrosinase buffered with McIlvaine buffer solution ( $\mathrm{pH} \mathrm{3,4,5,6}$ and 7 , respectively) were prepared and incubated at $37^{\circ} \mathrm{C}$ for 24 hrs. Thin-layer chromatogram of the ether extracts of each solution is shown in Fig. 6. Spots which were positive to a phenol test due to the presence II, III and IV were observed on each chromatogram. Another phenolic substance $\mathrm{V}$ was also observed on chromatograms obtained from the solutions of $\mathrm{pH} 3$ and 4.

Effect of the reaction time on the formation of these products at $\mathrm{pH} 3.0$ was examined by thin-layer chromatography (Fig. 7). II, III and IV did not appear at initial stage of the reaction, but later formed gradually. On the other hand, $V$ was already formed at initial stage simultaneously with $\mathrm{I}$, and the amount of $\mathrm{V}$ did not change in spite of a decrease of $I$. Therefore, it may be true that $\mathrm{V}$ was directly formed from sinalbin and not from I by its secondary decomposition. The results obtained by thin layer chromatography for the mustard paste were nearly identical with that in the case of the reaction mixtures.

Since $p$-hydroxybenzyl alcohol (II) was also a major product on the secondary decomposi-

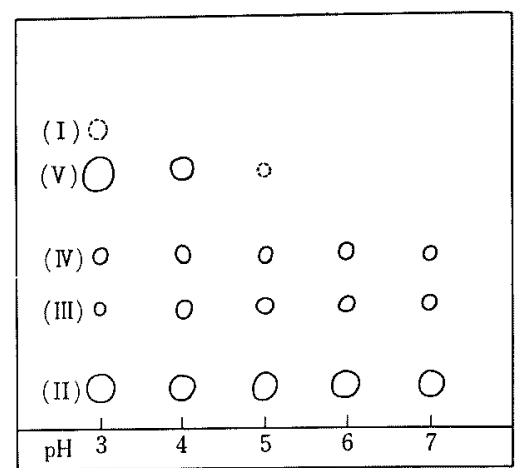

FIG. 6. Thin-layer Chromatogram of the Decomposition Products of Sinalbin at Several $\mathrm{pH}$.

Samples: ether extracts of the reaction mixtures of sinalbin and myrosinase ( $\mathrm{pH}$ of medium, $3,4,5,6$ and 7 , respectively) incubated at $37^{\circ} \mathrm{C}, 24 \mathrm{hrs}$.

Solvent: chloroform-ether (4:1).

Coloring reagent: diazotized sulfanilic acid and $10 \%$ sodium carbonate

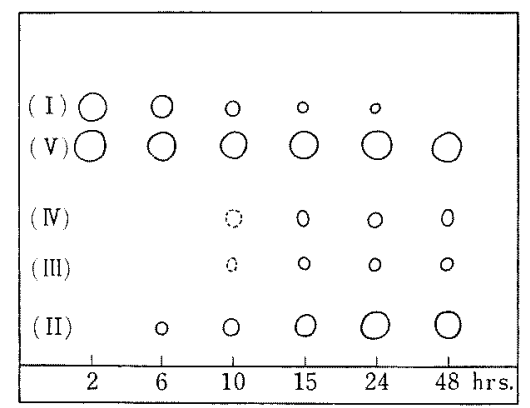

FIG. 7. Thin-layer Chromatogram of the Decomposition Products of Sinalbin at $\mathrm{pH} 3.0$ in Time Course.

Samples: ether extracts of the reaction mixtures of sinalbin and myrosinase at $\mathrm{pH} 3.0$ incubated at $37^{\circ} \mathrm{C}$ for $2,6,10,15,24$ and 48 hrs., respectively.

Solvent: chloroform-ether (4:1).

Coloring reagent: diazotized sulfanilic acid and $10 \%$ sodium carbonate

tion of I in acidic medium, the amount of $\mathrm{SCN}^{-}$formed in the reaction mixture of sinalbin and myrosinase was determined in 


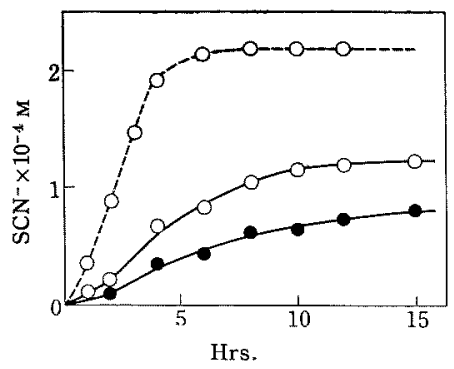

FIG. 8. Formation of SCN- from Sinalbin.

-O- Sinalbin and myrosinase at $\mathrm{pH}$ 3.0.

- - - - Sinalbin and myrosinase at $\mathrm{pH} 7.0$.

- Mustard paste at $\mathrm{pH} 3.0$.

The ordinate indicates the molar amount of SCNformed from $100 \mathrm{ml}$ of the reaction mixture or $\mathrm{lg}$ of the mustard powder.

time course. The results obtained are shown in Fig. 8. The rate of $\mathrm{SCN}^{-}$formation at $\mathrm{pH} 3.0$ was slower than that in the neutral medium ( $\mathrm{pH} \mathrm{7.0),} \mathrm{and} \mathrm{this} \mathrm{could} \mathrm{be} \mathrm{due} \mathrm{to} \mathrm{a}$ low activity of myrosinase at $\mathrm{pH} 3 . .^{9 !}$

After incubation for fifteen hours, during which I was mostly decomposed, the $\mathrm{SCN}^{-}$ formation did not occur any more. The amount of $\mathrm{SCN}^{-}$formed in the acidic medium was about a half of that formed in the neutral one, corresponded to about fifty four and ninety percent of the added sinalbin, respectively. This fact suggested that some other product, not formed through I, should be produced from sinalbin.

The facts mentioned above clearly showed that a new product $(V)$ was formed from sinalbin directly in acidic medium, and this compound $(\mathrm{V})$ isolated from the reaction mixture by ether extraction, followed by column chromatography on silica gel. Recrystallization from water gave plates, m.p. $71^{\circ} \mathrm{C}$. The elementary analyses of $\mathrm{V}$ supported $\mathrm{C}_{8} \mathrm{H}_{7} \mathrm{NO}$ for its molecular formula. IR spectrum (Fig. 9) showed the presence of $p$-substituted phenol group (3380, 1613,

9) Z. Nagashima and M. Uchiyama, J.Agr. Chem. Soc. Japan, 33, 484 (1959).

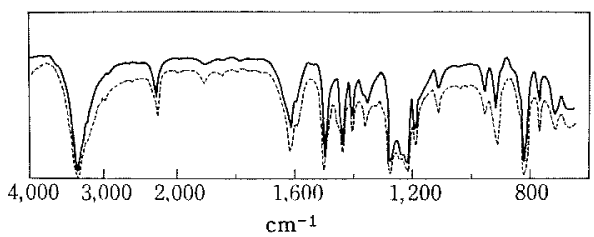

FIG. 9. IR Spectra of the Product V.

— isolated, -..- synthesized

$1600,1503,1213$ and $813 \mathrm{~cm}^{-1}$ ) and $-\mathrm{C} \equiv \mathrm{N}$ group $\left(2280 \mathrm{~cm}^{-1}\right)$. From these results, $V$ was assumed to be $p$-hydroxybenzyl cyanide, and the sample obtained from the natural source was identical in every respects (m.p., IR and chromatographic behaviour) with a synthetic one derived from $p$-hydroxybenzyl alcohol. Sulfur was also isolated as $\mathrm{S}_{8}$, m.p. $119^{\circ} \mathrm{C}$ from ether extracts of the reaction mixture. Therefore, it was demonstrated that sinalbin was decomposed under acidic condition as follows:

sinalbin $\rightarrow p$-hydroxybenzyl isothiocyanate (I) $\downarrow p$-hydroxybenzyl cyanide $(\mathrm{V})+$ sulfur

Total degradation scheme of sinalbin was summerized in Fig. 10. As shown in above experiments, $p$-hydroxybenzyl $p$-hydroxybezyldithiocarbamate (III) is so unstable that it is possible that the actual decomposition of III in mustard paste to di-( $p$-hydroxybenzyl) disulfide (IV), $p$-hydroxybenzylamine (VI) and carbonyl sulfide might proceed without any action of enzyme. However, it remains unsolved whether or not the formation of III from I (especially formation of the $p$-hydroxybenzyl-S linkage) is enzymatical process. With respects to this, A. I. Virtanen et al. ${ }^{10 \sim 111}$ reported interesting facts that benzyl isothiocyanate formed from glucotropaeolin in the seeds of Lepidium sativum was converted to benzyl thiocyanate (benzyl-S linkage) with some isomerase contained in the seeds.

10) A. I. Virtanen and M. Saarivirta, Suomen Kemistilehti, B35, 102, 428 (1962).

11) M. Saarivirta and A.I. Virtanen, Acta Chem. Scand., 17, S74 (1963). 


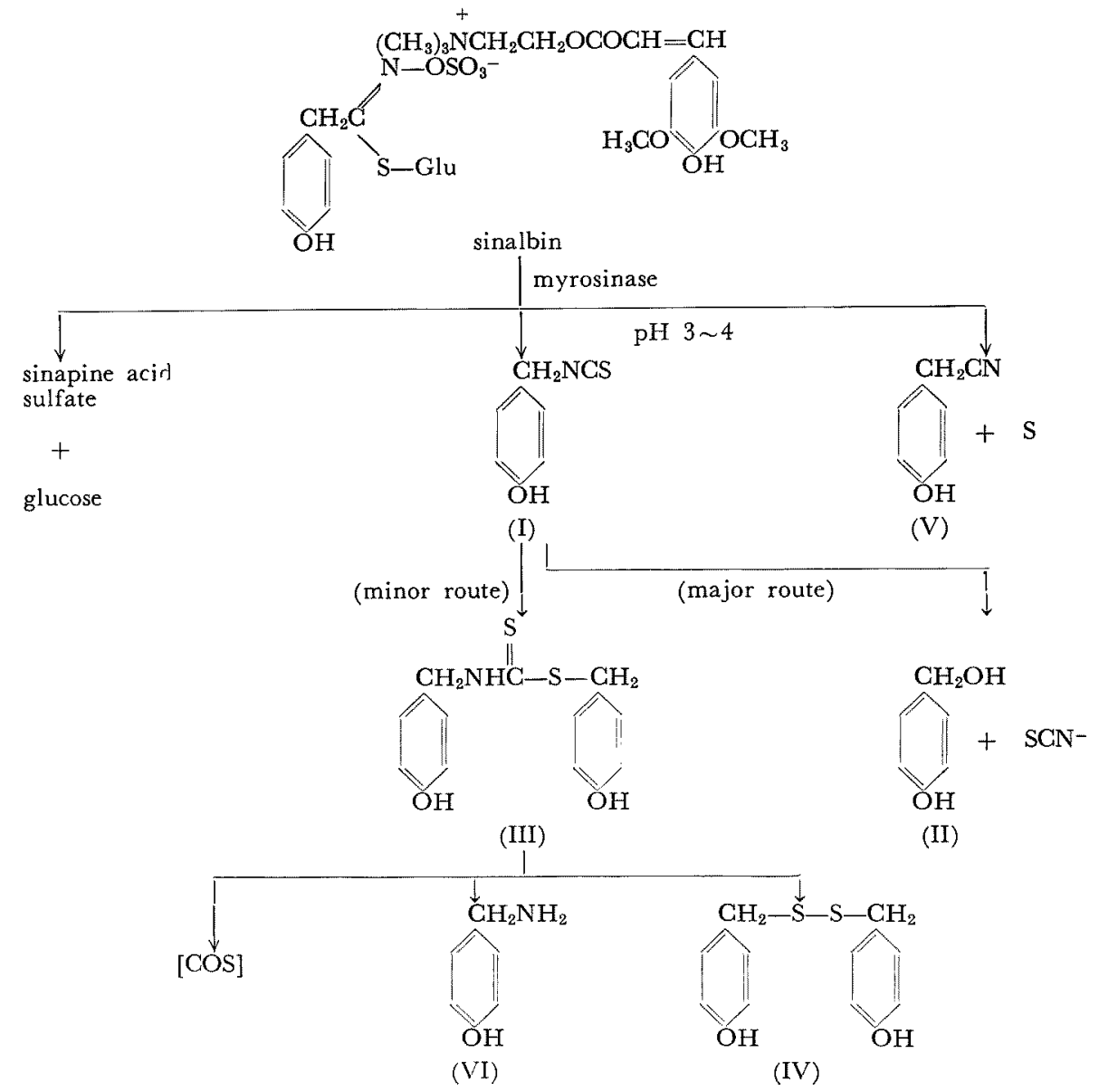

FIG. 10. Total Degradation Scheme of Sinalbin.

Myrosinase used in our experiments was not such a pure preparation that it might be contaminated by such characteristic enzyme. There have been many studies ${ }^{3 \sim 5,12,13 !}$ on the secondary decomposition of mustard oils, but no experiments have yet been made on the formation of disulfide from mustard oil through dithiocarbamate. D. A. Forss ${ }^{(1)}$ demonstrated

12) E. B. Astwood, M. A. Greer and M. G. Ettlinger, J. Biol. Chem, 181, 121 (1949).

13) A. Kjaer and Bo W. Christensen, Acta Chem. Scand., 13, 1575 (1959).

14) D. A. Forss, Australian J. Applied Sci., 2, 396 (1951) that an essential oil obtained from Coronopus didymus a cruciferous weed, by steam distilation, contained benzyl cyanide and dibenzyl disulfide, but he did not describe on their precursors. It seems likely that the decomposition of isothiocyanate to disulfide through dithiocarbamate occurs in the nature besides the present study of white mustard.

\section{EXPERIMENTAL}

All melting points were uncorrected. UV spectra were measured in 95\% ethanol with Hitachi-Perkin Elmer 139 and Hitach EPS-2; IR spectra with JASCO IR-S and Hitachi EPI-2 in KBr disks. Mass spectra 
were measured with Hitachi Mass Spectrometer RMU$6 \mathrm{D}$.

\section{Isolation and Chemical Structure of the Product III}

Isolation of III. Mustard paste, which was prepared with defatted powder of white mustard $(800 \mathrm{~g})$ and Mcllvaine buffer, $\mathrm{pH} 4.0,(1200 \mathrm{ml})$, was incubated at $37^{\circ} \mathrm{C}$ for $48 \mathrm{hrs}$. To the paste, ethanol (31) was added and the mixture was well agitated and kept at room temperature for overnight. After centrifugation of this mixture, the precipitate was repeatedly extracted with ethanol. The ethanol extracts were combined and concentrated under reduced pressure to remove ethanol. The concentrated solution was extracted with ether, and the ether extract was dried on anhydrous sodium sulfate and concentrated. The ether extract was chromatographed over silica gel using chloroform-ether $(90: 10 \mathrm{v} / \mathrm{v})$ and fractionated every $50 \mathrm{ml}$. Each fraction was submitted to thin-layer chromatography and the fractions containing III were combined. On repeating the column chromatography, crude crystals III were obtained. After treatment with chloroform to remove resinous materials, recrystallization was carried several times from dilute ethanol to give colorless plate. M.p. $152^{\circ} \mathrm{C}$, yield $180 \mathrm{mg}$. M.w. 305 by mass spectrometry (Fig. 3). Anal. Found: C 58.97, H 4.75, N 4.74, S 20.94. Calcd. for $\mathrm{C}_{15} \mathrm{H}_{15} \mathrm{NO}_{2} \mathrm{~S}_{2}$ : C 59.01, H 4.95, N 4.59, S $20.97 \%$ (m.w. calcd. 305). UV spectrum is shown in Fig. 1: $\lambda_{\max }^{\mathrm{EtOH}} 229,257$ and $269 \mathrm{~m} \mu$ ( $\log \varepsilon 4.40,4.18$ and 4.15). IR spectrum is shown in Fig. 2. Solubility: easily soluble in ether, acetone, ethanol and methanol; sparlingly soluble in benzene, chloroform and water.

Alkaline hydrolysis of 1II. A solution of III $(10 \mathrm{mg})$ in ether $(5 \mathrm{ml})$ was shaken with three $2 \mathrm{ml}$ portions of $1 \mathrm{~N} \mathrm{NaOH}$. The alkaline solution was neutralized to $\mathrm{pH} 6.0$ with $5 \mathrm{~N} \mathrm{H}_{2} \mathrm{SO}_{4}$ and extracted with ether. The water and ether layers were concentrated to a small volume respectively, and submitted to paper and thin-layer chromatography. $p$ Hydroxybenzylamine was detected in the water solution, and di-( $p$-hydroxybenzyl)disulfide and $p$-hydroxybenzyl alcohol were in the ether solution. During the neutralization of the alkaline solution, evolution of hydrogen sulfide was detected by lead acetate paper.

Synthesis of $\boldsymbol{p}$-Hydroxybenzyl $\boldsymbol{p}$-Hydrox ybenzyldithiocarbamate

i) p-Hydroxybenzylamine hydrochloride. This compound was synthesized from $p$-hydroxybenzaldehyde by the method described by A. Kjaer et al.7)

M.p. $197^{\circ} \mathrm{C}$. Anal. Found: C 52.19, H $5.76, \mathrm{~N}$ 8.80. Calcd. for $\mathrm{C}_{7} \mathrm{H}_{10} \mathrm{NOCl}$ : $\mathrm{C} 52.67, \mathrm{H} 6.31, \mathrm{~N}$ $8.77 \%$.

ii) Sodium $p$-hydroxybenzyldithiocarbamate. To a mixture of the above amine hydrochloride $(2 \mathrm{~g})$ in methanol $(60 \mathrm{ml})$ and sodium hydroxide $(1.5 \mathrm{~g})$ in water $(10 \mathrm{ml})$, an ether solution of carbon disulfide $(1 \mathrm{~g})$ was added dropwise with stirring for 30 minutes and followed with stirring for additional 30 minutes. After concentration of the reaction mixture under reduced pressure below $30^{\circ} \mathrm{C}$, large amount of cooled acetone was added to the concentrate to give white precipitates. The precipitates were collected and dissolved in methanol to remove insoluble matters (mostly sodium chloride) by filtration. The methanol solution was concentrated and cooled acetone was added again, and the precipitates were collected, washed with ether and dried. Sodium p-hydroxybenzyldithiocarbamate was obtained as hygroscopic powder (yield, $1.9 \mathrm{~g}$ ).

iii) p-Acetoxybenzyl chloride. This compound was prepared from $p$-hydroxybenzyl alcohol by the method of R. Grice et al.8)

iv) $p$-Acetoxybenzyl $p$-Hydroxybenzyldithiocarbamate. To a stirred solution of sodium $p$ hydroxybenzyldithiocarbamate $(1.9 \mathrm{~g})$ in methanol, $p$-acetoxybenzyl chloride $(2.8 \mathrm{~g})$ in methanol was added. The stirring was continued further for one hour. The solution was concentrated and the residual oil was extracted with boiling benzene. The benzene extracts were concentrated to dryness. The residue was purified by column chromatography on silica gel using chloroformether, and p-acetoxybenzyl $p$ hydroxybenzyldithiocarbamate was obtained $1.23 \mathrm{~g}$ as an oil.

v) p-Hydroxybenzyl $p$-Hydroxybenzyldithiocarbamate. A solution of $p$-acetoxybenzyl $p$-hydroxybenzyldithiocarbamate $(1.23 \mathrm{~g})$ in methanol was acidified with acetic acid and left to stand at room temperature overnight. The solution was concentrated, and the residue was extracted with ether. Thin-layer chromatography showed that this ether extracts contained $p$-hydroxybenzyl $p$-hydroxybenzyldithiocarbamate, di-( $p$-hydroxybenzyl)disulfide and the starting material. The reaction mixture was chromatographed on silica gel using chloroform-ether and fractionated every $50 \mathrm{ml}$. The presence of $p$-hydroxybenzyl $p$ hydroxybenzyldithiocarbamate was tested by thin- 
layer chromatography, and the fractions containing the dithiocarbamate were combined, concentrated and purified by repeated column chromatography on silica gel until it became chromatographically homogeneous on silica gel plate. After evaporation of the solvent, the residue was crystallized in refrigerator and recrystallized from dilute ethanol to give colorless plates of $p$-hydroxybenzyl $p$-hydroxybenzyldithiocarbamate. Yield, $0.22 \mathrm{~g} \mathrm{m.p.} 152^{\circ} \mathrm{C}$ (decomp.). Anal. Found: C 59.21, H 4.94, N 4.51, S 21.04 . Calcd. for $\mathrm{C}_{15} \mathrm{H}_{15} \mathrm{NO}_{2} \mathrm{~S}_{2}$ : C 59.01, H $4.95, \mathrm{~N} 4.59$ S $20.97 \%$. The UV spectrum (Fig. 1) showed $\lambda_{\max }^{\mathrm{EtOF}}$ 229, 257 and $269 \mathrm{~m} \mu(\log \varepsilon 4.39,4.18$ and 4.14) and the IR spectrum is shown in Fig. 2.

2. Decomposition of Sinalbin in Acidic Condition Sinalbin and myrosinase used in this experiments were prepared from mustard powder by the procedures described in the previous paper. ${ }^{11}$

Thin-layer Chromatography of Decomposition Products in Acidic Medium

i) Effect of $\mathbf{p H}$ on sinalbin decomposition. The reaction mixtures composed of $2.4 \times 10^{-4} \mathrm{M}$ sinalbin (25 ml), myrosinase solution $(25 \mathrm{ml})$ and McIlvaine buffer solution ( $\mathrm{pH}, 3,4,5,6$ and 7 , respectively) $(50 \mathrm{ml})$ were incubated at $37^{\circ} \mathrm{C}$ for $24 \mathrm{hrs}$, and then extracted with ether. The ether extracts were dried over anhydrous sodium sulfate and concentrated. The decomposition products in the extracts were detected by thin-layer chromatography on silica gel (solvent, chloroform-ether $4: 1 \mathrm{v} / \mathrm{v}$ ). Phenolic spots were developed by spraying diazotized sulfanilic acid solution, followed by $10 \%$ sodium carbonate solution. The chromatogram are shown in Fig. 6. Four spots were detected as the phenolic decomposition products in acidic medium.

ii) Sinalbin decomposition in time course. Six reaction mixtures of $\mathrm{pH} 3.0$ were incubated at $37^{\circ} \mathrm{C}$ and extracted with ether one after another at 2, 6, $10,15,24$ and 48 hrs., respectively. The ether extracts were subjected to thin-layer chromatography as mentioned above (Fig. 7).

Quantitative Analysis of Thiocyanate Ion in Reaction Mixtures

SCN-formed in the reaction mixture was determined by the colorimetric method described in the previous paper1) (Fig. 8).

\section{Isolation of $\mathrm{V}$}

The reaction mixture, which consisted of sinalbin ( $3 \mathrm{~g}$ in $375 \mathrm{ml}$ of water), myrosinase solution $(375 \mathrm{ml}$ ) and McIlvaine buffer solution ( $750 \mathrm{ml}, \mathrm{pH} \mathrm{3.0}$ ), was incubated at $37^{\circ} \mathrm{C}$ for $24 \mathrm{hrs}$. and extracted with ether. The ether solution was dried with anhydrous sodium sulfate and concentrated. Yellow substance was crystallized from the concentrate and recrystallized from $n$-hexane to give pale yellow prisms, m.p. $119^{\circ} \mathrm{C}$. It was identified as $\mathrm{S}_{8}$ by the mixed melting point with authentic $S_{8}$. The concentrate was submitted to column chromatography on silica gel using chloroform-ether. Fractions containing V were combined and concentrated to give crystals. Recrystallization from water afforded plates of $\mathrm{V}$, m.p. $71^{\circ} \mathrm{C}$, yield $50 \mathrm{mg}$. Anal. Found: C 71.97, H 5.29, N 9.95. Calcd. for $\mathrm{C}_{8} \mathrm{H}_{7} \mathrm{NO}$ : C 72.16, $\mathrm{H} 5.30, \mathrm{~N} 10.52 \%$.

Synthesis of p-Hydroxybenzyl Cyanide and Identification of the Product $V$

To a solution of sodium cyanide $(5 \mathrm{~g})$ in water $(10 \mathrm{ml}), p$-acetoxybenzyl chloride $(10 \mathrm{~g})$ (cf. 1-iii)) in $95 \%$ ethanol $(30 \mathrm{ml})$ was slowly added and the mixture was refluxed for $4 \mathrm{hrs}$. The reaction mixture was filtered to remove sodium chloride and concentrated. The concentrate was refluxed with $2 \mathrm{~N}$ hydrochloric acid in methanol $(50 \mathrm{ml})$ for $2 \mathrm{hrs}$. and then evaporated to brown oil. The oil was dissolved in boiling benzene, cooled and crystallized. Recrystallization from water afforded plates, m.p. $72^{\circ} \mathrm{C}$, yield $2.3 \mathrm{~g}$. Anal. Found: C 72.33, H 5.24, N 10.49 . Calcd. for $\mathrm{C}_{8} \mathrm{H}_{7} \mathrm{NO}$ : C 72.16, H 5.30, N 10.52\%.

The mixed melting point with $\mathrm{V}$ was $71^{\circ} \mathrm{C}$. The isolated and synthetic samples were identical in respect to IR spectra (Fig. 9) and thin-layer chromatographic behaviours.

Acknowledgement. We wish to express our thanks to Professor K. Munakata and Dr. $H$. Aoki, the Nagoya University for helpful guidance and encouragement, and to Dr. $H$. Honma, the Institute of Physical and Chemical Research and to Misses M. Hamaji and K. Nakane, this University for elementary analyses. 